\title{
COVID-19 as Industry Forcing Function: Challenges for Entrepreneurship in the Post-Pandemic Future
}

\author{
Olga Belousova ${ }^{\text {a }}$ \\ Assistant Professor, o.belousova@rug.nl \\ Steven Walsh ${ }^{\mathrm{b}}$ \\ Distinguished Professor,walsh@unm.edu \\ Aard Groen a \\ Professor, a.j.groen@rug.nl \\ a Groningen University, Kadijk 4, 9747 AT Groningen, The Netherlands \\ ${ }^{\mathrm{b}}$ University of New Mexico, 618 Cedar Hill Rd. NE, Albuquerque, NM - 87122, United States
}

\begin{abstract}
$\mathrm{T}$ he COVID-19 crisis has changed how firms and industries do business - at least for now. What is uncertain, is the duration of that change. Will the industry change induced by the COVID-19 crisis persist and, if so, for how long? Can a crisis, and particularly the COVID-19 crisis, act as a more permanent change agent and create an environment that mimics the entrepreneurial opportunity that industry forcing functions create? If yes, then there is cause to consider the entrepreneurial opportunity that the COVID-19 crisis provides.

In this paper, we review the changes that the pandemic has brought to business practices. Furthermore, we discuss the differences between crisis-based opportunity and entrepreneurial opportunity created by industry forcing functions in order to illuminate the ability of a COVID-19 crisis-induced Low Touch Economy to sustainably create entrepreneurial opportunities. We show examples and list

the attributes of industry forcing functions that have already provided sustainable entrepreneurial opportunity. Then, we match these attributes with the factors related to the COVID-19-related Low Touch Economy.

We find that the COVID-19 crisis has similarities and differences to traditional industry forcing functions started by disruptive technologies. However, unlike traditional industry forcing functions, the COVID-19 crisis acts in a pan-industrial manner, making the impact of the pandemic more profound. Furthermore, the timing of the pandemic is important: the COVID-19 crisis struck during the emergence of a Schumpeterian wave of Industry 4.0 and accelerated the adoption of its most important harbingers. We provide researchers and practitioners a lens through which to review not only the COVID-19 crisis's possibility of lasting effects, but also how it will affect entrepreneurs.
\end{abstract}

Keywords: COVID-19; pandemic; crisis; entrepreneurship; industry forcing function; low touch economy

Citation: Belousova O., Walsh S., Groen A. (2021) COVID-19 as Industry Forcing Function: Challenges for Entrepreneurship in the Post-Pandemic Future. Foresight and STI Governance, 15(4), 33-41. DOI: $10.17323 / 2500-2597.2021 .4 .33 .41$ 


\section{Introduction}

Even in 2021, COVID-19 still continues to affect the everyday lives of people, organizations, and countries. This crisis stressed our society and revealed health, economic, and political vulnerabilities. Worldwide lockdowns limited global and domestic flow of travel and trade $[\mathrm{Ho}$, Maddrell, 2021]. FFurther significant changes have been observed in how business is conducted creating the Low Touch Economy that practitioners and academics alike are debating about to determine whether it will sustainably shape future consumer behavior [Santos Vieira de Jesus et al., 2020; Sheth, 2020].

As socioeconomic, cultural, and political relations are being reconfigured due to the pandemic, we witness disruptions in business practices, leading to major uncertainty about the future. Currently, businesses of all sizes are rapidly adopting novel digital technologies [Liguori, Pittz, 2020; Sharma et al., 2020] and leveraging their local and virtual communities [Floetgen et al., 2021] in order to remain resilient and agile during the crisis. The pandemic appears to have changed the basic assumptions we held about business and social life [Anker, 2021]. However, it still remains to be seen whether these changes will stay once everything is back to normal [Sheth, 2020].

While crises are usually major and negative events, they can create opportunities for starting or changing a business [Doern et al., 2019]. Will the COVID-19-induced Low Touch Economy lead to the sustained generation of entrepreneurial opportunities [Stanciu et al., 2020]? There is a group of socioeconomic change agents that have created sustainable entrepreneurial opportunity and academics refer to this group as industry forcing functions. ${ }^{1}$ Industry forcing functions can be regulatory, technological, or policy-driven. For example, the US Clean Air Act of 1970 changed how the automobile industry did business and eventually initiated the development of a new industry [Gerard, Lave, 2005] through sustained entrepreneurial opportunity. These types of regulation initiate an innovation express for those with entrepreneurial capacity. Technology-based forcing functions often create supplementary industries - such as, in this case, the development of the "cleanroom industry" [Chavez et al., 2017] - by stimulating entrepreneurial action in new and existing firms. An example of a policy-based forcing function is the Marshall Plan [Agnew, Entrikin, 2004] that also created long-lasting entrepreneurial opportunities. But what about the COVID-19 pandemic and the policies, regulations, and technologies surrounding it? To assess the potential of the COVID-19 crisis to create lasting entrepreneurial opportunities, we discuss the factors unique to the COVID-19 pandemic and how these factors compare to industry forcing functions.
We show how the COVID-19 crisis induced the Low Touch Economy, which is a great match to industry forcing functions. However, one major difference is that industry forcing functions usually start out in a single industry and then expand to others. The COVID-induced Low Touch Economy is unique due to its pan-industrial nature. This aspect of the pandemic has an exceptionally large impact upon entrepreneurial opportunity. We establish that the pandemic's panindustrial nature alone can serve as a forcing function to induce the generation of new ideas, inventions, and innovations. Yet, the pandemic has also accelerated the disruptive Schumpeterian wave of Industry 4.0. Implications for research and practice are discussed.

\section{COVID-19 Crisis and Shifts in the Economy}

Most definitions describe a crisis as an "extreme, unexpected, or unpredictable event that requires an urgent response from organizations" [Doern et al., 2019, p. 401]. Although there are different types of crises, all of them have three elements in common: surprise, threat, and a short response time [Durst, Henschel, 2021]. The COVID-19 crisis is no exception. Furthermore, it is also transboundary. On the one hand it easily cuts across geographical and policy boundaries [Boin, Lodge, 2016]. On the other hand, it also crosses industrial boundaries and affects a wide range of industries and sectors simultaneously [Ivanov, Dolgui, 2020].

In fact, the coronavirus pandemic clearly has an impact on virtually all manufacturers, retailers, and wholesalers globally. According to [Ivanov, 2020] 94\% of the Fortune 1000 companies experienced coronavirus-driven supply chain disruptions and that at least 5 million companies globally rely on at least one tierone or tier-two supplier in the Wuhan region of China, COVID-19's origin. Beyond the disruption of the direct supply chain activities, the coronavirus measures led to the creation of the Low Touch Economy [Santos Vieira de Jesus et al., 2020] and caused simultaneous disturbances in both supply and demand, initiating a ripple effect and performance degradation in terms of revenue, service level, and productivity [Ivanov, Dolgui, 2020].

The Low Touch Economy refers to a new state of the economy, a result of the COVID-19 pandemic control and mitigation health measures that led to behavior shifts and economic disruption [Santos Vieira de Jesus et al., 2020]. Companies in the context of the Low Touch Economy have to adapt their business models, create high impact innovations, and flexibly navigate the pandemic's aftershocks in the global economy, and do so with respect to the new hygiene measures and constraints on business-as-usual. These measures

http://news.unm.edu/news/anderson-school-s-innovation-group-to-help-new-mexicos-businesses-respond-to-covid-19-management-challenges, accessed 09.09.2021. 
include the substitution of offline events for virtual ones, the reduction of physical interactions between employees and consumers, the use of online tools and apps to interact and work, travel bans, limitations on large gatherings, and the isolation of vulnerable groups [Santos Vieira de Jesus et al., 2020].

The low touch aspect is very important for understanding the impact and entrepreneurial opportunity that the COVID-19 crisis presents, and it has a profound impact on both the content and the process of the business practices as we know it. Analyzing previous crises, such as the 2008-2009 global financial crisis, research suggests that the service side of businesses was much less disrupted and even the manufacturing sector could rely on the maintenance and after-sales services in order to compensate for the production disruption [Rapaccini et al., 2020]. In the current situation, however, services have become highly complicated (if not put on hold) due to the national lockdowns and international travel bans. The current trends that emerge as a result of these disruptions include: uncertainty of demand, an increase in the role of technology in search for agility, and increased focus on collaboration, social, and environmental innovation [Sharma et al., 2020]. We further expand upon these trends.

\section{Uncertainty in Demand}

In the past year, certain sectors, such as automobiles, crude oil, and transportation, have experienced a tremendous decline in demand due to COVID-19 restrictions. Yet, the business areas necessary to facilitate remote working, online education, and the supply of essential goods and services have witnessed explosive growth [Anker, 2021]. Certain businesses, like firms operating in the healthcare sector, were forced to match demand-supply equations on a daily basis [Sharma et al., 2020]. What is common in these changes across the sectors is the inherent unpredictability of the change.

The COVID-19 crisis is an example of such change originating not from human agency, but rather brought upon by natural forces beyond human control. This crisis truly challenged the main assumption of the current business practice: predictability that promoted efficiency as the dominant criteria of success [Anker, 2021]. Almost overnight, lean, efficient, and planned-to-the-second operations that used to be a core capability became a core rigidity, to rephrase Leonard-Barton [Leonard-Barton, 1992]. The uncertainty that the pandemic brought, required firms to transition from the "planning soloist" mindset to the "hedging networker" approach to business [Harms et al., 2021]. Both business and governments engaged in developing multiple parallel diversification initiatives, developing policies and collaborations to overcome the disruptions caused by COVID-19, and transition until things return to normal.
Under the assumption of uncertainty, a diversification strategy with three or more distinct and independent supply chains for the same process allows businesses to become less reliant on one large market, region, or nation [Anker, 2021]. Making use of a similar idea of reducing reliance on the predictability of global operations, more and more companies turn to their local ecosystems. Previously, such decisions have been described in the contexts of sanctions and forced isolation of countries, such as Iran [Aliasghar et al., 2020]. Nowadays, however, examples come from a variety of industries spanning from emergency response and $3 \mathrm{D}$ printing of lung ventilators [Belhouideg, 2020] to hospitality businesses hustling within their local ecosystem to create new partnerships and compensate for the closure of the hotels and restaurants, and cancellation of events [Harms et al., 2021]. Technology harbingers of Industry 4.0 definitely provide new means to support local supply chains [Walsh, 2001]. The move from mass production to mass customization brought on by one of the technologies underpinning Industry 4.0-3D printing - made supply lines shorter [Elders et al., 2001].

This use of Industry 4.0 technologies increases diversification, which, in turn, increases resilience. The entrepreneurial action comes, however, from recognizing change and rapidly taking advantage of it. Agility and flexibility are important aspects of the entrepreneurial mindset [Shepherd et al., 2010; Hattenberg et al., 2020] and are often based on major technological improvements-in our case those technologies underpinning Industry 4.0.

\section{Increased Role of Technology}

Technology has emerged as an important factor that determines the success or failure of a firm during COVID-19 [Sharma et al., 2020]. Currently, firms simultaneously adopt numerous technologies that can give them visibility across the value chain. Furthermore, firms also adopt technologies that help in improving efficiency and agility in the context of the Low Touch Economy [Sharma et al., 2020]. These technologies include digital platforms [Ruutu et al., 2017; Floetgen et al., 2021], innovative logistics solutions [Rapaccini et al., 2020], predictive analytics, and systems based on Internet of Things [Paiola, Gebauer, 2020; Rapaccini et al., 2020]. At the service of multinational retailers such as Amazon, they were critically important to enable the governmental lockdowns: without the multinational retailers' vast supply chain ecosystem and logistic solutions, and their willingness to quickly adapt operations to support governments' emergency policies, lockdowns would have been impossible [Anker, 2021].

Furthermore, digitalization has also democratized the marketplace, opening up novel opportunities for connecting with customers. Virtual business channels challenge business models of traditional entrepreneur- 
ship [Nambisan, 2017], but provide a unique opportunity to reinvigorate the search for product-market fit and the hunt for new business models capable of surviving and thriving in a COVID-19-impacted world [Liguori, Pittz, 2020]. In fact, among all of the digitalization projects, technologies that are closely linked to the development of advanced service and digital offerings (e.g., connected products and data valorization, diagnostic and preventive maintenance, customer relationship management, and ticketing and troubleshooting to provide remote assistance) are currently accelerating at the highest speed [Rapaccini et al., 2020].

However, digitalization brings not only opportunities, but also challenges. The highly iterative nature of digital products and services requires entrepreneurs and small businesses to quickly acquire the corresponding competencies and resources for effective deployment [Liguori et al., 2020]. This means that the strong capabilities developed in one sphere of the business may become core rigidities [Leonard-Barton, 1992] unless the business is capable of transforming them at an ever-increasing speed, transitioning from ordinary to dynamic capabilities [Teece, 2014]. This transition will, however, put additional strain on resources and capabilities, which are not always readily available, especially in younger and smaller firms [Sapienza et al., 2006] or minority-owned businesses [Walsh, Linton, 2011; Neumeyer et al., 2020] that traditionally lack resources and competencies for experimentation and development.

\section{Social Innovation for Resilience}

In the search for resilience, researchers also note, along with the technology, there was an upheaval of the consideration for humans and human capital. The COVID-19 pandemic has profound socio-psychological, physical, and technical implications for entrepreneurs and employees [Carnevale, Hatak, 2020]. It is described as a "growing interest in personal well-being that minimizes person-to-person contact due to the experience of the pandemic" [Lee, Lee, 2021, p. 5]. Since the COVID-19 pandemic required businesses and people to reconfigure their forms of sociality [Santos Vieira de Jesus et al., 2020], digital servitization came as a solution for business to reach out to customers in the Low Touch Economy reality [Rapaccini et al., 2020]. Kirk and Rifkin [2020] even suggest that the pandemic has changed who we are as humans: the exponential increase in digital technology that replicates social interaction pushes the boundaries between human and machine, leading to digitally mediated sociality.

Yet, despite the digitalization and the Low Touch Economy, the shared goal of controlling the spread of COVID-19 renewed the importance of a sense of community [Lee, Lee, 2021], transforming the ultimate form of recognition from the individual achievement into the acknowledgement of care for others. For example, in the first months of the COVID-19 lockdown, the ride-sharing provider, BlaBlaCar, has successfully introduced a new platform - "BlaBlaHelp"-through which communities can support one another with grocery shopping and delivery of essential items, including medicines. Within 72 hours, more than 20,000 people registered on the platform. This occurrence has further increased not only awareness about the platform but also the trust in BlaBlaCar's values and services, which additionally resulted in a significant increase in summer holiday bookings via its platform [Floetgen et al., 2021].

The Low Touch Economy induced by COVID-19 has, therefore, changed how firms operate (shifting the managerial focus from eliminating slacks in search of efficiency toward building resilience to counteract uncertainty), how they compete (changing the praised hero from an achiever to someone who supports the community and cares for others), where they compete (moving transactions to the digital marketplace basically overnight), and the tools they use to do so (as we can witness in the ever-increasing technology adoption rates). However, disruption oftentimes brings about the most significant innovations and improvements [Christensen, 1997]. Numerous voices suggest that the pandemic will result in major societal shifts and that it will bring long-lasting positive outcomes [Kirk, Rifkin, 2020].

\section{COVID-19 Crisis as a Source of Opportunity}

While crises are usually major and negative events, they can lead to new opportunities for starting or changing a business [Doern et al., 2019] and fuel business expansion [Eggers, 2020]. A crisis can act as "an external enabler" [Davidsson, 2015], triggering new products, services, and venture ideas, enhancing outcomes of new and ongoing ventures, and reshaping existing products and ventures [Davidsson et al., 2021; Doern et al., 2019]. Yet, previous research has shown that crises can also stretch institutions to the limit, rendering standard operating procedures inapplicable and severely testing professional norms [Boin, Lodge, 2016]. This is due to the departure from the pre-existing systems, procedures, and capabilities that novel ventures can be highly effective at alleviating suffering [Shepherd, Williams, 2014]. Hence, the uncertainty of the COVID-19 crisis may be the source of life-changing disruptions as well as a possibility for future development [Springer, 2020].

In the context of the COVID-19-induced Low Touch Economy and uncertainty, we note an accelerated adoption of novel technologies that allow for higher agility and resilience of both businesses and communities [Rapaccini et al., 2020]. Where television, social media, and other transformational technologies often took years to achieve widespread adoption, many of the digital and technological offerings currently introduced face few or no barriers in the process of active experimentation and adaptation to the Low Touch Economy induced by COVID-19 [Kirk, Rifkin, 2020]. 
In healthcare, digital health has been accelerated [Lee, Lee, 2021] and telemedicine is said to have reclaimed center stage [Marin, 2020]. For manufacturing firms, the post-COVID-19 era could finally experience the massive adoption of industrial internet, condition monitoring, predictive maintenance, digital rooms, augmented and virtual reality, and digital twins in services and solutions [Rapaccini et al., 2020].

As digital technologies have profound effects on entrepreneurial processes [von Briel et al., 2017], these changes offer novel challenges and opportunities for the entrepreneurs of tomorrow. Entrepreneurial companies are those innovative, proactive, and risk-taking actors that pioneer new markets, discovering new opportunities and actively experimenting to address them [Miller, 1983; Shane, Venkataraman, 2000]. The value entrepreneurs place on autonomy, their tolerance of uncertainty, and their ability to approach new situations openly and proactively often help them thrive in highly uncertain and demanding environments, such as the COVID-19 crisis [Carnevale, Hatak, 2020]. It is the combination of the proactive entrepreneurial and market orientations that allows companies to overcome or even benefit from challenges imposed by the crisis [Eggers, 2020]. When incumbents actively hedge their options based on what is within their control, monitoring their actions appears to bring limited benefits as compared to capitalizing upon the upcoming technologies, market trends, and opportunities [Beliaeva et al., 2020; Walsh, Kirchhoff, 2003]. The digitalization brought by the COVID-19-induced Low Touch Economy opened up novel channels for entrepreneurs to connect with their stakeholders [Liguori, Pittz, 2020]. Those small and agile players have the advantage of building their ventures ex nihilo based on novel approaches and technologies. Furthermore, abundant in the digital world, specific sources of social support-such as positive feedback from customers-may ultimately enhance the entrepreneurs' wellbeing in the context of the Low Touch Economy of reduced physical and social interaction in daily business conduct [Carnevale, Hatak, 2020]. This proactive orientation and flexibility to follow the market is why young firms have a greater likelihood of surviving during crisis periods than they do during growth periods [Simón-Moya et al., 2016].

In contrast, the extent to which the new technology advances remain an integral part of the economy depends largely on whether the recent legislative and regulatory changes become permanent [Marin, 2020]. As COVID-19 spread across the globe, governments responded with denial; over-provisioning or panicbuying; obsessive cleanliness; various forms of protectionism; exertion of control over others; and more positive supportiveresponses, such as business support, enhancing capacity of healthcare andmutual aid [Maddrell, 2020; Springer, 2020]. With lockdowns and other low touch economy creating measures, governments forced to work outside established routines and practices, each country tends to respond in its own manner, mostly influenced by the standards adopted by national experts advising their governments on pandemic responses [Baekkeskov, 2016]. Under uncertainty and urgency, the potential for evidence-based policy is indeed limited, but to sustain the momentum created by COVID-19, it is necessary that legislation evolves together with science and technology.

As we are now in the middle of a lasting disruption, it is difficult to say what the post-COVID world will look like and whether it will continue creating sustained entrepreneurial opportunities. The pandemic experience is unprecedented in modern history, making it difficult to find a relevant reference point for comparison and informed foresight. Several authors have compared the COVID-19 crisis to earlier pandemics [Stanciu et al., 2020], natural disasters (for example, in political elections) [James, Alihodzic, 2020], and to the financial crisis of 2008 [Chen, Yeh, 2021]. In this article, we choose to take a different angle. Since the Low Touch Economy has a profound impact upon the technology adoption curve and requires institutions to adapt quickly, we seek inspiration in two examples of industry forcing function - the technological forcing function of Willis Whitfield's cleanroom [Chavez et al., 2017] and the regulatory-based forcing function of the US Clean Air Act [Gerard, Lave, 2005].

\section{Industry Forcing Functions}

Willis Whitfield invented the modern-day cleanroom. This is how Cleanroomtechnology (2012) describes it: "The laminar-flow cleanroom created a work environment that was more than 1,000 times cleaner than the cleanrooms in use at the time. Within a few short years, $\$ 50$ billion worth of laminar-flow cleanrooms were being built worldwide and the invention is used in hospitals, laboratories, and manufacturing plants today." ${ }^{2}$ This has revolutionized manufacturing in electronics, changed the safety standards for hospital operating rooms, and stimulated further space exploration.

Passed in 1970, the Clean Air Act is the other example we want to mention here. It became one of modern America's most consequential laws. Translated into real-world rules by the newly established Environmental Protection Agency, the act has since reduced air pollution in the United States by 70 percent-even as the population, the economy, and the number of cars on roads have grown [Gardiner, 2020]. Since lawmakers wrote the act to evolve along with scientific and technological advances, it has stood the test of time [Gardiner, 2020] and has not only impacted the citizens' duration of life but also saved trillions of dollars [Gerard, Lave, 2005].

Although of a different nature, both disruptive innovations-the cleanroom and the Clean Air Act-can be

\footnotetext{
${ }^{2}$ https://cleanroomtechnology.com/news/article_page/A_revolutionary_invention/82304, accessed 15.05.2021.
} 
considered industry forcing functions. They have created lasting change by rendering the existing order of things obsolete and undesirable [Linton, Walsh, 2004] and drove the market toward the envisioned future standard [Davidsson, 2004]. Will the COVID-19 crisis, which disrupted our daily lives so profoundly and made us reassess the basic assumptions about business practice, sociality, and community, have a similar lasting effect in the future?

\section{COVID-19 as a Forcing Function}

Although regulation and policies can be industry forcing functions, most global economies have thus far enacted legislation and policies designed to have firms transition the pandemic. That is, the legislation and policies aim to support companies until the COVID-19 pandemic can be overcome and firms return to the pre-COVID dynamics of doing business [Fakhruddin et al., 2020]. These transition support policies and regulations do little to provide an entrepreneurial opportunity. Furthermore, individual countries react to COVID-19 in diverse manners [Baekkeskov, 2016], complicating a sustained response from businesses. These efforts alone would not have created a lasting change.

However, regulations that promote social distancingand foster the Low Touch Economy-have already created entrepreneurial opportunities, among them those linked to digitalization [Scheidgen et al., 2021; Liguori, Pittz, 2020]. Since the COVID-19 pandemic is still upon us and we observe that despite the vaccination efforts, new variants emerge and countries exit and enter lockdowns in an a-synchronized manner, we conclude that the world will carry on with a certain form of social distancing, making the move back to the old normal unlikely. We argue that this aspect of the COVID-19 pandemic creates entrepreneurial opportunity and acts like an industry forcing function.

However, while most industry forcing functions are based on technology or regulatory change, the COVID-19 crisis is based on disease transference and affects all and any industries independent of the technologies they use. The COVID-19 crisis is, thus, panindustrial and creates these opportunities in many industry sectors. In fact, COVID-19 changes how we work and live [Ratten, 2020]. It has affected how we socialize, interact, and reward each other both as individuals and as a community [Anker, 2021; Lee, Lee, 2021]. Moreover, COVID-19 changes the discussions in supply chain management and shifts the focus from a simple financial consideration to a resilience and sustainability strategy [Sharma et al., 2020]. Once this strategy is implemented, this does not appear likely to change. However, a projection of the duration of these changes remains unexplored.

One manner in which to understand the duration of the impact that the current pandemic crisis brings, is to ask whether the COVID-19 pandemic has affected the Schumpeterian wave of Industry 4.0. The COVID-19 crisis occurred during the emergence of Industry 4.0 and, to a certain extent, the two are now intertwined. The Low Touch Economy induced by the crisis has affected both the supply side and the demand side of businesses and created a market-pull demand for disruptive technology [Walsh, Kirchhoff, 2003; Walsh et al., 2002]. Since the adoption of technologies grew faster in order to combat the pandemic's consequences, the technologies underpinning Industry 4.0 , such as block chain, Internet of Things, and additive manufacturing have been put to a much broader use [Paiola, Gebauer, 2020; Rapaccini et al., 2020]. Furthermore, as the change occurs in a pan-industrial manner, it gained broader acceptance and legitimacy, leading to more entrepreneurial opportunities and less resistance from the societal and regulatory sides [Kirk, Rifkin, 2020]. There is, therefore, evidence that the COVID-19 pandemic has accelerated the use of Industry 4.0's underpinning technologies and therefore affected and accelerated the Schumpeterian wave [Cros et al., 2021].

\section{Discussion and Conclusion}

Although crises and industry forcing functions have similar characteristics, they do, however, differ in duration. Industry forcing functions like policy, regulation, and technology development cause the creative destruction of industry standard products [Linton, Walsh, 2004]. Yet, they also create opportunities to redefine specific marketplaces and create new ones. A crisis most often affects many industries at the same time and is pan-industrial. Numerous policies are initially considered to transit the bad times. If the policies are successful and a crisis is transited, these types of crisis tend to be regionally limited like the crisis of the German pension system [Sinn, 1999]. Other crises are not transited as well. These other crises take on aspects of an industry forcing function and do so in a pan-industrial manner.

The Great Depression is one of those crises that did not transit well. The generation that lived through the Great Depression [Aitkin et al., 1970] had long-lasting, ingrained thoughts toward banks and labor unions, and they translated their experience into politics, policy, and regulations, which many regard as the roots of World War II, as the psychology of the people changed and populations as a whole felt they had a lot less to lose [Rogler, 2002]. However, the Great Depression also created a generation that wished to create stable world economies and social justice [Brokaw, 2000].

Where does the COVID-19 pandemic and its resultant policies fit as a crisis? There is tremendous ambiguity and uncertainty involved in the COVID-19 pandemic [Durodié, 2020]. Two years into the crisis, a new variant of the virus, the Omikron variant, now re-intensifies the global pandemic. Not enough is known about our current vaccine's efficacy toward the new variant. Is the worst of the pandemic, therefore, behind us or is the worst yet to come? Certain lasting effects of the pan- 
demic are, however, already noted [Kirk, Rifkin, 2020]. Adapting to the new normal, companies have to innovate and increase their resilience and agility, but they need to do it in the context of new hygiene and health measures [Santos Vieira de Jesus et al., 2020]. The Low Touch Economy induced by COVID-19 has changed how firms compete, where they compete, and the tools they use to do so. Many predict that industry and firm supply chains will change dramatically and permanently due to COVID-19 [Anker, 2021; Sharma et al., 2020]. More importantly, the remote-working population is on the rise and many employers and workers regard this as beneficial and long lasting [Brynjolfsson et al., 2020; Carnevale, Hatak, 2020]. The pandemic has further accelerated the adoption of novel technologies that allow higher agility and resilience of both businesses and communities [Rapaccini et al., 2020; Kirk, Rifkin, 2020]. Future studies need to ascertain the effect that the COVID-19 pandemic has had in accelerating the embrace of Industry 4.0's technological harbingers. Initial studies on block chain [Marbouh et al., 2020], additive manufacturing [Larrañeta et al., 2020], arti- ficial intelligence [Ahuja et al., 2020], and Internet of Things [Alam et al., 2021] show that COVID-19 has indeed accelerated the disruptive, Schumpeterian wave of Industry 4.0 [Cros et al., 2021]. However, future research will have to follow closely how lasting these initial changes are. Furthermore, it is not clear whether these changes can fully replace business practice as we know it, or whether they will augment the portfolio of tools and strategies that businesses use instead. As such, we cannot yet predict whether, in the longer run, the global supply chains' efficiency will become less important than the flexibility and resilience achieved through local collaborations and partnerships, especially in higher costs areas such as the EU and the US. We also do not know whether these initial changes will be an effective strategy against possible new outbreaks of viruses like COVID-19. Furthermore, the numerous developments that the COVID-19 crisis has induced reside on different levels (from an individual to industry and to society as a whole) and are not necessarily in equilibrium. The pandemic's multi-level effects will also offer numerous future research avenues.

\section{References}

Agnew J., Entrikin J.N. (2004) The Marshall plan today: Model and metaphor, London, New York: Routlege.

Ahuja A.S., Reddy V.P., Marques O. (2020) Artificial intelligence and COVID-19: A multidisciplinary approach. Integrative Medicine Research, 9(3), 100434. https://doi.org/10.1016/j.imr.2020.100434

Aitkin D., Kahan M., Barnes S. (1970) What happened to the depression generation? Labour History, 17, 174-181.

Alam F., Almaghthawi A., Katib I., Albeshri A., Mehmood R. (2021) iResponse: An AI and IoT-enabled framework for autonomous COVID-19 pandemic management. Sustainability, 13(7), 3797. https://doi.org/10.3390/su13073797

Aliasghar O., Sadeghi A., Rose E.L. (2020) Process innovation in small- and medium-sized enterprises: The critical roles of external knowledge sourcing and absorptive capacity. Journal of Small Business Management (forthcoming). https://doi.org /10.1080/00472778.2020.1844491

Anker T.B. (2021) At the boundary: Post-COVID agenda for business and management research in Europe and beyond. European Management Journal, 39 (2), 171-178. https://doi.org/10.1016/j.emj.2021.01.003

Baekkeskov E. (2016) Same threat, different responses: Experts steering politicians and stakeholders in 2009 H1N1 vaccination policy-making. Public Administration, 94(2), 299-315. https://doi.org/10.1111/padm.12244

Belhouideg S. (2020) Impact of 3D printed medical equipment on the management of the COVID-19 pandemic. The International Journal of Health Planning and Management, 35(5), 1014-1022. https://doi.org/10.1002/hpm.3009

Beliaeva T., Shirokova G., Wales W., Gafforova E. (2020) Benefiting from economic crisis? Strategic orientation effects, tradeoffs, and configurations with resource availability on SME performance. International Entrepreneurship and Management Journal, 16, 165-194. https://doi.org/10.1007/s11365-018-0499-2

Boin A., Lodge M. (2016) Designing resilient institutions for transboundary crisis management: A time for public administration. Public Administration, 94 (2), 289-298. https://doi.org/10.1111/padm.12264

Brokaw T. (2000) The greatest generation, New York: Random House.

Brynjolfsson E., Horton J.J., Ozimek A., Rock D., Sharma G., TuYe H.Y. (2020) COVID-19 and remote work: An early look at US data (NBER Working Paper 27344), Cambridge, MA: National Bureau of Economic Research.

Carnevale J.B., Hatak I. (2020) Employee adjustment and well-being in the era of COVID-19: Implications for human resource management. Journal of Business Research, 116, 183-187. https://doi.org/10.1016/j.jbusres.2020.05.037

Chavez V.A., Stinnett R., Tierney R., Walsh S. (2017) The importance of the technologically able social innovators and entrepreneurs: A US national laboratory perspective. Technological Forecasting \& Social Change, 121, 205-215. https://doi. org/10.1016/j.techfore.2016.09.002

Chen H.C., Yeh C.W. (2021) Global financial crisis and COVID-19: Industrial reactions. Finance Research Letters, 101940. https://doi.org/10.1016/j.frl.2021.101940

Christensen C.M. (1997) The Innovator's Dilemma: When New Technologies Cause Great Firms to Fail, Boston, MA: Harvard Business School Press.

Cros M., Epaulard A., Martin P. (2021) Will Schumpeter Catch COVID-19? Evidence from France, London: Centre for Economic Policy Research. https://voxeu.org/article/will-schumpeter-catch-covid-19-evidence-france, accessed 17.09.2021.

Davidsson P. (2004) Researching Entrepreneurship, New York: Springer Science, Business Media, Inc. 
Davidsson P. (2015) Entrepreneurial opportunities and the entrepreneurship nexus: A re-conceptualization. Journal of Business Venturing, 30(5), 674-695.

Davidsson P., Recker J., von Briel F. (2021) COVID-19 as External Enabler of Entrepreneurship Practice and Research. Business Research Quarterly, 24(3), 214-223. https://doi.org/10.1177/23409444211008902

Doern R., Williams N., Vorley T. (2019) Special issue on entrepreneurship and crises: Business as usual? An introduction and review of the literature. Entrepreneurship \& Regional Development, 31(5-6), 400-412. https://doi.org/10.1080/08985626.20 18.1541590

Durodié B. (2020) Handling uncertainty and ambiguity in the COVID-19 pandemic. Psychological Trauma: Theory, Research, Practice, and Policy, 12(S1), S61-S62. https://doi.org/10.1037/tra0000713

Durst S., Henschel T. (2021) COVID-19 as an accelerator for developing strong(er) businesses? Insights from Estonian small firms. Journal of the International Council for Small Business, 2(1), 1-29. https://doi.org/10.1080/26437015.2020.1859935

Eggers F. (2020) Masters of disasters? Challenges and opportunities for SMEs in times of crisis. Journal of Business Research, 116, 199-208. https://doi.org/10.1016/j.jbusres.2020.05.025

Elders J., Spiering V., Walsh S. (2001) Microsystems Technology (MST) and MEMS Applications: An Overview. MRS Bulletin, 26(4), 312-315. https://doi.org/10.1557/mrs2001.69

Fakhruddin B.S., Blanchard K., Ragupathy D. (2020) Are we there yet? The transition from response to recovery for the COVID-19 pandemic. Progress in Disaster Science, 7, 100102-100102. https://doi.org/10.1016/j.pdisas.2020.100102

Floetgen R.J., Strauss J., Weking J., Hein A., Urmetzer F., Böhm M., Krcmar H. (2021) Introducing platform ecosystem resilience: Leveraging mobility platforms and their ecosystems for the new normal during COVID-19. European Journal of Information Systems, 30(3), 304-321. https://doi.org/10.1080/0960085X.2021.1884009

Gardiner B. (2020) This landmark law saved millions of lives and trillions of dollars. National Geographic, 29.12.2020. https:// www.nationalgeographic.com/environment/article/clean-air-act-saved-millions-of-lives-trillions-of-dollars, accessed 05.29.2021.

Gerard D., Lave L.B. (2005) Implementing technology-forcing policies: The 1970 Clean Air Act Amendments and the introduction of advanced automotive emissions controls in the United States. Technological Forecasting and Social Change, 72(7), 761-778. https://doi.org/10.1016/j.techfore.2004.08.003

Harms R., Alfert C., Cheng C.-F., Kraus S. (2021) Effectuation and causation configurations for business model innovation: Addressing COVID-19 in the gastronomy industry. International Journal of Hospitality Management, 95, 102896. https:// doi.org/10.1016/j.ijhm.2021.102896

Hattenberg D.Y., Belousova O., Groen A.J. (2020) Defining the Entrepreneurial Mindset and Discussing its Distinctiveness in Entrepreneurship Research. International Journal of Entrepreneurship and Small Business, 44(1). DOI: 10.1504/ IJESB.2021.10041401

Ho E.L.-E., Maddrell A. (2021) Intolerable intersectional burdens: A COVID-19 research agenda for social and cultural geographies. Social \& Cultural Geography, 22(1), 1-10. https://doi.org/10.1080/14649365.2020.1837215

Ivanov D. (2020) Predicting the impacts of epidemic outbreaks on global supply chains: A simulation-based analysis on the coronavirus outbreak (COVID-19/SARS-CoV-2) case. Transportation Research. Part E: Logistics and Transportation Review, 136, 101922. https://doi.org/10.1016/j.tre.2020.101922

Ivanov D., Dolgui A. (2020) Viability of intertwined supply networks: Extending the supply chain resilience angles towards survivability. A position paper motivated by COVID-19 outbreak. International Journal of Production Research, 58(10), 2904-2915. https://doi.org/10.1080/00207543.2020.1750727

James T.S., Alihodzic S. (2020) When Is It Democratic to Postpone an Election? Elections During Natural Disasters, COVID-19, and Emergency Situations. Election Law Journal: Rules, Politics, and Policy, 19(3), 344-362. https://doi.org/10.1089/ elj.2020.0642

Kirk C.P., Rifkin L.S. (2020) I'll trade you diamonds for toilet paper: Consumer reacting, coping and adapting behaviors in the COVID-19 pandemic. Journal of Business Research, 117, 124-131. https://doi.org/10.1016/j.jbusres.2020.05.028

Larrañeta E., Dominguez-Robles J., Lamprou D.A. (2020) Additive manufacturing can assist in the fight against COVID-19 and other pandemics and impact on the global supply chain. 3D Printing and Additive Manufacturing, 7(3), 100-103. https:// doi.org/10.1089/3dp.2020.0106

Lee S.M., Lee D. (2021) Opportunities and challenges for contactless healthcare services in the post-COVID-19 Era. Technological Forecasting and Social Change, 167, 120712. https://doi.org/10.1016/j.techfore.2021.120712

Leonard-Barton D. (1992) Core capabilities and core rigidities: A paradox in managing new product development. Strategic Management Journal, 13 (S1), 111-125. https://doi.org/10.1002/smj.4250131009

Liguori E.W., Phillips F., Neumeyer X., Mahto R.V., Santos S.C., Walsh S. (2020) Winds of change: The evolving relationship of entrepreneurship, small businesses, technology, and innovation. A Joint JSBM \& TFSC Call for Papers. https://www. researchgate.net/profile/Raj-Mahto/project/CFP-Joint-SI-for-JSBM-and-TSFC/attachment/5fe217b93b21a2000163bf6f/ AS:971574115069959@1608652728951/download/TSFC-JSBM+Final+CFP.pdf, accessed 15.09.2021.

Liguori E.W., Pittz T.G. (2020) Strategies for small business: Surviving and thriving in the era of COVID-19. Journal of the International Council for Small Business, 1(2), 106-110. https://doi.org/10.1080/26437015.2020.1779538

Linton J.D., Walsh S.T. (2004) Roadmapping: From sustaining to disruptive technologies. Technological Forecasting and Social Change, 71 (1-2), 1-3. https://doi.org/10.1016/j.techfore.2003.10.004

Maddrell A. (2020) Bereavement, grief, and consolation: Emotional-affective geographies of loss during COVID-19. Dialogues in Human Geography, 10(2), 107-111. https://doi.org/10.1177\%2F2043820620934947

Marbouh D., Abbasi T., Maasmi F., Omar I.A., Debe M.S., Salah K., Jayaraman R., Ellahham S. (2020) Blockchain for COVID-19: Review, Opportunities, and a Trusted Tracking System. Arabian Journal for Science and Engineering, 45(12), 9895-9911. https://doi.org/10.1007/s13369-020-04950-4 
Marin A. (2020) Telemedicine takes center stage in the era of COVID-19. Science (November), 731-733. https://www.science. org/content/article/telemedicine-takes-center-stage-era-covid-19, accessed 12.09.2021.

Miller D. (1983) The correlates of entrepreneurship in three types of firms. Management Science, 29, 770-791. https:/doi. org/10.1287/mnsc.29.7.770

Nambisan S. (2017) Digital Entrepreneurship: Toward a Digital Technology Perspective of Entrepreneurship. Entrepreneurship Theory and Practice, 41(6), 1029-1055. https://doi.org/10.1111\%2Fetap.12254

Neumeyer X., Santos S.C., Morris M.H. (2020) Overcoming Barriers to Technology Adoption When Fostering Entrepreneurship Among the Poor: The Role of Technology and Digital Literacy. IEEE Transactions on Engineering Management, 68(6), 16051618. https://doi.org/10.1109/TEM.2020.2989740

Paiola M., Gebauer H. (2020) Internet of things technologies, digital servitization and business model innovation in B2B manufacturing firms. Industrial Marketing Management, 89, 245-264. https://doi.org/10.1016/j.indmarman.2020.03.009

Rapaccini M., Saccani N., Kowalkowski C., Paiola M., Adrodegari F. (2020) Navigating disruptive crises through service-led growth: The impact of COVID-19 on Italian manufacturing firms. Industrial Marketing Management, 88, 225-237. https:// doi.org/10.1016/j.indmarman.2020.05.017

Ratten V. (2020) Coronavirus (COVID-19) and entrepreneurship: Changing life and work landscape. Journal of Small Business \& Entrepreneurship, 32(5), 503-516. https://doi.org/10.1080/08276331.2020.1790167

Rogler L.H. (2002) Historical generations and psychology: The case of the Great Depression and World War II. American Psychologist, 57(12), 1013-1023. https://doi.apa.org/doi/10.1037/0003-066X.57.12.1013

Ruutu S., Casey T., Kotovirta V. (2017) Development and competition of digital service platforms: A system dynamics approach. Technological Forecasting and Social Change, 117, 119-130. https://doi.org/10.1016/j.techfore.2016.12.011

Santos Vieira de Jesus D., Kamlot D., Jacubowski Correia Dubeux V. (2020) Innovation in the 'New Normal' Interactions, the Urban Space, and the Low Touch Economy: The Case of Rio de Janeiro in the Context of the COVID-19 Pandemic. International Journal of Social Science Studies, 8(5), 17-27. https://doi.org/10.11114/ijsss.v8i5.4900

Sapienza H.J., Autio E., George G., Zahra S.A. (2006) A Capabilities Perspective on the Effects of Early Internationalization on Firm Survival and Growth. The Academy of Management Review, 31(4), 914-933. https://doi.org/10.5465/amr.2006.22527465

Scheidgen K., Gümüsay A.A., Günzel-Jensen F., Krlev G., Wolf M. (2021) Crises and entrepreneurial opportunities: Digital social innovation in response to physical distancing. Journal of Business Venturing Insights, 15(6), e00222. https://doi. org/10.1016/j.jbvi.2020.e00222

Shane S., Venkataraman S. (2000) The promise of entrepreneurship as a field of research. Academy of Management Review, 25(1), 217-228. https://doi.org/10.2307/259271

Sharma A., Adhikary A., Borah S.B. (2020) Covid-19's impact on supply chain decisions: Strategic insights from NASDAQ 100 firms using Twitter data. Journal of Business Research, 117, 443-449. https://doi.org/10.1016/j.jbusres.2020.05.035

Shepherd D.A., Patzelt H., Haynie J.M. (2010) Entrepreneurial spirals: Deviation-amplifying loops of an entrepreneurial mindset and organizational culture. Entrepreneurship Theory and Practice, 34(1), 59-82. https://doi.org/10.1111\%2Fj.15406520.2009.00313.x

Shepherd D.A., Williams T.A. (2014) Local Venturing as Compassion Organizing in the Aftermath of a Natural Disaster: The Role of Localness and Community in Reducing Suffering. Journal of Management Studies, 51(6), 952-994. https://doi. org/10.1111/joms.12084

Sheth J. (2020) Impact of COVID-19 on consumer behavior: Will the old habits return or die? Journal of Business Research, 117, 280-283. https://doi.org/10.1016/j.jbusres.2020.05.059

Simón-Moya V., Revuelto-Taboada L., Ribeiro-Soriano D. (2016) Influence of economic crisis on new SME survival: Reality or fiction? Entrepreneurship \& Regional Development, 28(1-2), 157-176. https://doi.org/10.1080/08985626.2015.1118560

Sinn H.W. (1999) The Crisis of Germany's Pension Insurance System and How it Can be Resolved (NBER Working Paper w7304), Cambridge, MA: National Bureau of Economic Research.

Springer S. (2020) Caring geographies: The COVID-19 interregnum and a return to mutual aid. Dialogues in Human Geography, 10(2), 112-115. https://doi.org/10.1177\%2F2043820620931277

Stanciu S., Radu R.I., Sapira V., Bratoveanu B.D., Florea A.M. (2020) Consumer Behavior in Crisis Situations. Research on the Effects of COVID-19 in Romania. Economics and Applied Informatics, 26(1), 5-13. https://doi.org/10.35219/eai1584040975

Teece D.J. (2014) The Foundations of Enterprise Performance: Dynamic and Ordinary Capabilities in an (Economic) Theory of Firms. The Academy of Management Perspectives, 28(4), 328-352. https://www.jstor.org/stable/43822373

von Briel F., Davidsson P., Recker J. (2017) Digital Technologies as External Enablers of New Venture Creation in the IT Hardware Sector. Entrepreneurship Theory and Practice, 42(1), 47-69. https://doi.org/10.1177\%2F1042258717732779

Walsh S. (2001) Portfolio Management for the Commercialization of Advanced Technologies. Engineering Management Journal, 13(1), 33-37. DOI: 10.1109/IEMC.1998.727803

Walsh S.T., Kirchhoff B. (2003) Entrepreneurs Opportunities in Technology-based Markets. In: Technological Entrepreneurship (ed. P. Phan), Greenwich, CT: Information Age Publishing, pp. 17-31.

Walsh S.T., Kirchhoff B.A., Newbert S. (2002) Differentiating market strategies for disruptive technologies. IEEE Transactions on Engineering Management, 49(4), 341-351. DOI: 10.1109/TEM.2002.806718

Walsh S.T., Linton J.D. (2011) The strategy-technology firm fit audit: A guide to opportunity assessment and selection. Technological Forecasting and Social Change, 78, 199-216. https://doi.org/10.1016/j.techfore.2010.06.023 